\title{
PROJETO E DESENVOLVIMENTO DE UM JOGO DIDÁTICO NA ÁREA DE SEGURANÇA DO TRABALHO PARA ALUNOS DE ENGENHARIA E CURSOS TÉCNICOS
}

\author{
Cibelle dos Santos Carlos (UFERSA-RN, Brasil) cibellecarlos@hotmail.com \\ Raquel Ferreira de Negreiros (UFERSA-RN, Brasil) raquel-negreiros@hotmail.com \\ Maria Aridenise Macena Fontenelle (UFERSA-RN, Brasil) aridenise.macena@gmail.com
}

Resumo: $O$ estudo da área de Segurança do Trabalho trouxe, para o ambiente de trabalho, benefícios para as empresas e melhorias no rendimento de seus funcionários. Assim, existem algumas metodologias capazes de auxiliar no processo de conhecimento dessa área. É de total importância que o funcionário comece a aprender e entender os riscos do trabalho no seu período de formação acadêmica. Os jogos didáticos estão inseridos como uma dessas ferramentas que auxiliam na aprendizagem e vem sendo utilizado em sala de aula de diversas universidades com o intuito de ajudar o aluno a fixar o conhecimento de muitas áreas do conhecimento. Dessa maneira, foi feito um estudo para criação de um jogo, chamado Trilha Segura, objetivando mostrar os conceitos de Segurança do trabalho, baseados em conceitos básicos e na NR-18, para os estudantes de cursos de engenharias e técnico. Trata-se de um jogo didático, de perguntas e respostas, que coloca duas equipes concorrentes para avançar numa trilha à medida que forem acertando as perguntas. Para o projeto do produto em questão, foram feitos estudos bibliográficos e pesquisas de mercado, para em seguida ser elaborado o protótipo do jogo.

Palavras-chave: Segurança do Trabalho. NR-18. Jogos Didáticos. Trilha Segura.

Abstract: The study area of Occupational Safety brought to the work environment, benefits for businesses and improvements in the performance of their employees. Thus, some methods can assist in this area of knowledge process. It is all important that the official start to learn and understand the risks of the work in its period of academic training. The educational games are included as one of those tools that help in learning and has been used in the classroom in various universities in order to help the student fix the knowledge of many fields of knowledge room. Thus, a study to create a game called Safe Trail was made, aiming to show the concepts of Job Security, based on basic concepts and NR-18, for students in engineering and technical courses. It is an educational game of questions and answers, which pits two teams competing to advance a track as they are hitting questions. For the design of the product in question, bibliographic studies and market research, for then the prototype of the game being drafted were made.

Keywords: Safety at work. NR-18. Didactic games. Safe trail. 


\section{Introdução}

Ao entrar nas universidades, os estudantes recebem uma tempestade de informações, conceitos, conteúdos e conhecimentos que deverão aprender e fixar para que consigam serem bons profissionais no mercado onde irão atuar. Porém, a "sala de aula" não leva ao aluno a prática de toda a teoria que ensina. De certa maneira, a informação sempre será um bem intangível que será usado para a realização de alguma tarefa, ou serviço. O processo de saber transformar o conhecimento em prática é um processo importante na formação do aluno. Atualmente o grupo de alunos universitários não é formado somente por alunos que acabaram de sair do ensino médio. Mas também por pessoas com uma idade mais avançada, que possuem famílias e trabalham quase o dia todo, necessitando, portanto, de exemplos práticos que facilitem o aprendizado. Pois o tempo de estudo desse grupo de alunos é limitado. Entretanto, os jovens alunos, recém-formados no ensino médio. Também buscam maneiras práticas de aprender toda a teoria vista em sala de aula para que possam aumentar a segurança nas tomadas de decisões quando forem "jogados" no mercado de trabalho.

Assim, a criação e aplicação de jogos didáticos em sala de aula possibilita o desenvolvimento de habilidades e promove a aprendizagem. Segundo Pazda, et al. (2009), apud Kishimoto (1996), o jogo didático é uma opção viável para ajudar nos processos de ensinoaprendizagem, pois favorece na criação do conhecimento do aluno. O jogo didático é usado em sala de aula para melhorar o desempenho dos alunos em alguns conteúdos, que causam mais dificuldade no entendimento teórico.

\section{Objetivos}

\subsection{Objetivos gerais}

Os O objetivo é transmitir informações através de um jogo simples e de fácil entendimento, que seja criativo, útil e prático. A princípio, o jogo foi desenvolvido para ser utilizado pelos alunos dos cursos de engenharia e nível técnico, mas não é descartada a possibilidade de expandir a sua abrangência e atingir outros públicos.

\subsection{Objetivos específico}

- Estudar os temas jogos, segurança do trabalho e aprendizagem didática;

- Apresentar os resultados obtidos na criação do jogo

\section{Metodologia}

A metodologia utilizada no projeto do produto em questão foi feita da seguinte maneira:

1. Idealização do produto

2. Investigação do cenário

3. Visualização do objetivo

4. Criação do projeto

5. Criação do produto

6. Análise do produto e viabilidade de sua prática 


\section{ReLAInEF}

Inicialmente foi proposta a ideia de um jogo didático que envolvesse a área de Segurança do Trabalho, para auxiliar no entendimento dos assuntos teóricos.

Assim, foi feita uma pesquisa bibliográfica, buscando referências sobre o assunto e opiniões á respeito dos resultados da aplicação desses jogos. A partir disso, obteve-se uma lista de ideias, temas e assuntos que poderiam ser abordados no jogo, para em seguida focar no projeto final do que seria o objetivo do jogo. A pesquisa levou em consideração que características de agilidade, praticidade, lógica, utilidade e criatividade fossem essenciais para o desenvolvimento do produto final. Dessa maneira, foram iniciados os estudos e pesquisas a respeito de jogos didáticos e as ideias do produto foram surgindo. As melhores opiniões, conceitos e dicas foram estabelecendo e dando inicio a criação do jogo didático em questão: Um jogo que auxilie nos conhecimentos teóricos dos alunos de engenharia e cursos técnicos, e desenvolva conhecimentos pragmáticos no estudante.

$\mathrm{O}$ produto escolhido, um jogo didático na área de segurança do trabalho, foi desenvolvido relevando características importantes, como:

- $\quad$ Criatividade

- $\quad$ Praticidade

- $\quad$ Simplicidade

- $\quad$ Custos adequados

- Utilidade

Segundo Rozenfeld et al. (2006), os estágios do projeto de produto seguiu o roteiro apresentado a seguir.

3.1 Biodiversidade e integração de espécies vegetais nativas à tecnologia "Telhado Vivos"

\section{FIGURA 1: MODELO DE DESENVOLVIMENTO DE PRODUTOS}

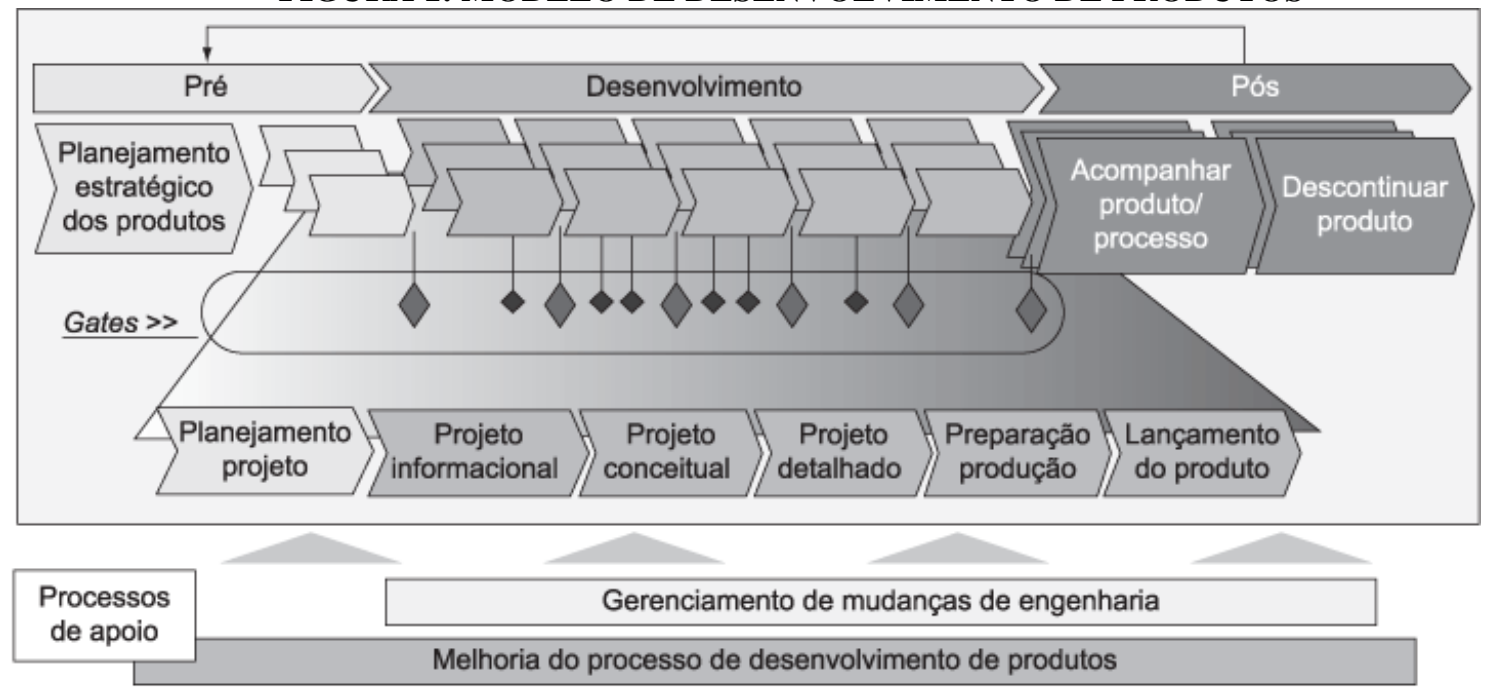

Fonte: Rozenfeld, 2006

Para a viabilização do produto, fez-se necessário uma pesquisa em campo, do tipo qualitativa, através de entrevistas, aplicação de questionário para análise de requisitos a ser desenvolvido no produto. Assim, inicia-se a fase do projeto conceitual, com todas as ideias 
coletadas nas etapas anteriores. Em seguida, após a concretização das ideias e conceitos, foi feita a definição dos materiais a serem utilizados, cálculos dos custos para a viabilização do jogo e desenho do mesmo. Então, uniu-se todos os componentes necessários à preparação da produção do produto e por fim, o produto foi composto e lançado.

\section{Referencial teórico}

\subsection{Processo de desenvolvimento de} produtos

Segundo Rozenfeld et al. (2006), Processo de desenvolvimento de produtos, PDP, é um processo de negócio que seleciona desde a ideia inicial, colocando o levantamento de informações do mercado que irá pretende atuar, as possíveis potencialidades tecnológicas e estratégicas dos produtores até a homologação do produto que atenda as necessidades do cliente, a um custa viável.

Segundo Slack et al. (2009), os produtos estão no topo da lista do que os clientes veem primeiro em uma empresa. Um projeto desenvolvido de maneira que agrade esses clientes, é capaz de trazer lucros à empresa aliado a satisfação das necessidades atuais e futuras desses consumidores. Como qualquer etapa de um projeto, o processo segue as seguintes etapas (Figura 2):

\section{FIGURA 2: PROCESSO DE UM PRODUTO/SERVIÇO}

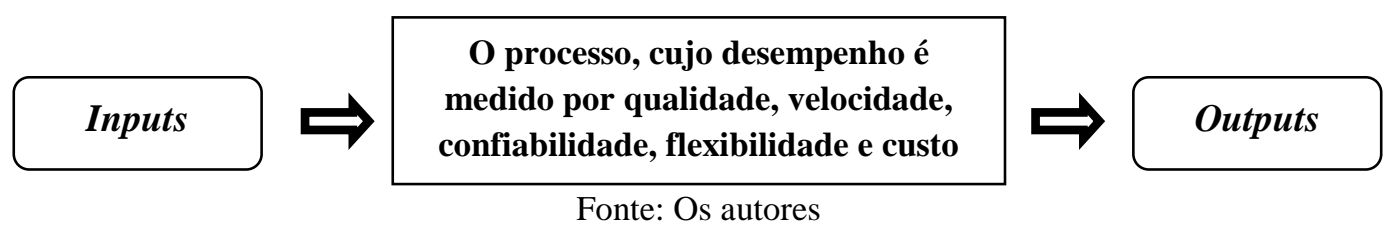

De acordo com Rozenfeld et al. (2006), desenvolver produtos é uma prática de um conjunto de atividades, por meio das quais se procura, a partir das necessidades do mercado e das possibilidades e restrições tecnológicas. E ponderando as estratégias competitivas e de produto da empresa, chegar às especificações de projeto de um produto e, também, de seu processo de produção.

\subsection{Segurança do trabalho}

Segundo Chiavenato (1999) a segurança, higiene e medicina no trabalho caracteriza-se por uma relação de custo/beneficio. As empresas devem fornecer os equipamentos necessários à proteção do trabalhador, visando manter a sua saúde e integridade, além do bom rendimento do processo produtivo de sua empresa. Como cita Torreira (1999), a utilização de equipamentos de proteção individual, ou EPI, diminui e evitar a ocorrência de lesões e outros fatores de risco ao funcionário. Machado (2002) afirma que fatores como saúde e segurança das pessoas diariamente e, principalmente, em seus ambientes profissionais, oferecem qualidade de vida e satisfação do operário.

De acordo com Araujo (2006), as empresas 
devem garantir que suas operações e atividades sejam atingidas de maneira segura e saudável para os seus empregados, cumprindo os requisitos legais de saúde e segurança, regidos pela Consolidação das Leis Trabalhistas (CLT) e Normas Regulamentadoras que tratam de Segurança e Saúde ocupacional.

Dessa forma, cada vez mais, as organizações buscam e se preocupam com a segurança do trabalhador, a fim de alcançar melhorias em seus processos, garantir a saúde e bem estar de seus funcionários e obter um bom rendimento, aumentando assim suas vantagens competitivas no mercado.

\subsection{NR - 18 Condições e meio ambiente de trabalho na indústria da construção}

A Norma Regulamentadora 18 (NR 18) define regras de prevenção para acidentes do trabalho para a indústria da construção e tem por objetivo estabelecer diretrizes para implementação de medidas de controle nas condições de trabalho, segurança e meio ambiente na indústria da Construção Civil.

Esta norma foi aprovada pela portaria $\mathrm{n}^{\circ} 3.214$ de 08/07/1978, porém, com o passar do tempo ficou defasada, necessitando de alterações. Entretanto, na reformulação da mesma, a grande maioria de seus itens continuou tratando apenas das condições físicas de trabalho oferecidas ao trabalhador havendo poucos itens demonstrem preocupação com o comportamento deste no ambiente de trabalho.

Dentro da NR 18 existe um item contendo o Programa de Condições e Meio Ambiente de
Trabalho na Indústria da Construção PCMAT. São obrigatórios a elaboração e o cumprimento do PCMAT nos estabelecimentos com vinte trabalhadores ou mais. O PCMAT deve ser apresentado a todos os trabalhadores, demonstrando sua importância e, principalmente, sua função de estabelecer os procedimentos de segurança.

A norma também trata de diversos aspectos relacionados aos itens que devem ter no canteiro de obras bem como a garantia de condições de conforto e higiene.

\subsection{Utilização de jogos didáticos}

De acordo com Romanel (2009) os jogos têm sido aplicados mais frequentemente desde os anos 1990 em salas de aula bem como em organizações, servindo como alternativa aos métodos tradicionais de ensino. Segundo Faria (1995), na concepção piagetiana, os jogos consistem numa simples assimilação funcional, que gera um sentimento de prazer pela ação lúdica e pelo domínio sobre as ações. "O jogo é necessário ao processo de desenvolvimento do ser humano e tem uma função vital para o indivíduo” (ROMANEL, 2009 apud PASSERINO, 2009).

\section{Desenvolvimento do jogo}

\subsection{Escopo do projeto}

O desenvolvimento de um jogo didático, voltado à área de segurança do trabalho para auxílio de ensino em universidades e cursos técnicos, é classificado como 
produto de informação e conhecimento. Dessa maneira, a ideia surgiu como forma de auxiliar os estudantes no aprendizado, partindo do pressuposto que os alunos gostariam de receber motivações e aulas dinâmicas a respeito do assunto para melhor fixação do conteúdo. Assim, foi idealizado o produto voltado à área de Segurança do Trabalho. Essa área foi à escolhida por ser abrangente a todos os cursos na área de engenharia, bem como cursos técnicos. Além de ser um ponto de bastante relevância dentro das empresas e do mercado de trabalho. Visto que a cada dia, nota-se a necessidade de informação nessa área para evitar acidentes ou erros no trabalho.

\subsection{Escopo do produto}

$\mathrm{O}$ produto em questão nesse projeto tem como objetivo principal unir a teoria e a prática dentro da sala de aula, visando o melhoramento do aprendizado do público alvo desse produto. O jogo deve permitir a dinâmica entre os alunos, com perguntas e dicas sobre a área abordada, bem como incentivar o trabalho em equipe e a competitividade. $\mathrm{O}$ conteúdo do jogo será disponibilizado em uma pasta, com todos os papéis e objetos necessários para sua funcionalidade. Vale ressaltar que o jogo, aqui abordado, está em fase de desenvolvimento e, possivelmente, poderá ser melhorado futuramente, não descartando a possibilidade de alterar o material utilizado para elaboração do mesmo, visando uma melhor qualidade no produto. O jogo contará com um tabuleiro, com cartas de perguntas e dicas, dados comuns e dois peões que serão utilizados para representar as equipes.

\subsection{A equipe responsável e as técnicas de pesquisa}

Para a elaboração do produto seja possível, faz-se necessário à responsabilidade, disciplina e comprometimento dos idealizadores do jogo, bem como de todos os envolvidos indiretamente com o projeto. A realização de tarefas, pesquisas e estudos, aliado ao auxílio humano são de total importância para o sucesso da ideia em questão, visto que para que o jogo seja colocado em prática, necessita que todos os pontos, citados anteriormente, sejam considerados e colocados em prática.

Ao ser feito todos os procedimentos necessários para a realização do produto, é necessário o seu aprimoramento através da prática do jogo, que irá concretizar o sucesso do projeto. Para isso, é essencial que sejam feitos pesquisas na área de jogos didáticos, segurança do trabalho, jogos de tabuleiro, para análise de dicas, regras e procedimentos utilizados nesse tipo de jogo, possibilitando a identificação dos pontos favoráveis ao produto e que se encaixam no que foi idealizado nesse trabalho. Dessa maneira, técnica de observação de outros jogos didáticos, entrevista com os possíveis usuários, para saber analisar a importância e o interesse no jogo, e brainstorming foram utilizadas para identificar esses pontos favoráveis. 
Este jogo, que permite a avaliação de técnicas que ajudam na diminuição dos riscos no ambiente de trabalho envolvendo a área de segurança do trabalho, foi desenvolvido por Cibelle dos Santos Carlos e Raquel Ferreira de Negreiros, alunas do curso de Engenharia de Produção da Universidade Federal Rural do Semi-Árido, com auxílio da Professora Dra. Maria Aridenise Macena, para ser aplicado em cursos e ajudar os alunos estudantes de Engenharias e Nível Técnico.

O principal enfoque do jogo é trazer dinâmica e prática para a sala de aula, com situações frequentemente encontradas no ambiente de trabalho. Situações como:

- Segurança, com base nos conceitos básicos da área e conhecimento da NR-18;

- Prevenção e Controle de riscos em máquinas, equipamentos e instalações;

- Uso de Equipamentos de Proteção Individual (EPI);

- Comunicação e Treinamento;

- Higiene no trabalho;

- Ergonomia e iluminação; e
- Proteção contra incêndios

Lembrando que as perguntas e dicas têm base em conhecimentos gerais da área de Segurança do Trabalho, com base nas NR'S que contem conceitos básicos e situações que possam ocorrer no ambiente profissional e, também, utilizou conceitos da NR-18, para elaboração dos questionamentos, visto que essa NR fala das condições e meio ambiente de trabalho na indústria da construção, setor que está em grande expansão no país.

O jogo propõe usar estratégias que eliminem situações que contribuem para a ocorrência de acidentes de trabalho e diminuam riscos no ambiente profissional.

\subsection{Planejamento e criação do produto}

Para chegar à ideia final do produto, foi feito um brainstorming e uma breve pesquisa entre os possíveis usuários do jogo, para saber como seria a aceitação do mesmo e também para buscar novas ideias.

O Quadro 1 mostra o questionário aplicado com os possíveis usuários.

\section{QUADRO 1: QUESTIONÁRIO APLICADO AOS POSSÍVEIS USUÁRIOS}

\begin{tabular}{|c|c|c|c|c|c|}
\hline \multirow[t]{2}{*}{ Marque as opções de 1 a 5 para avaliar, considerando "1" pouco importante e "5" muito importante. } & & & & & \\
\hline & 1 & 2 & 3 & 4 & 5 \\
\hline 1. Qual a importância de um jogo didático em sala de aula? & & & & & \\
\hline 2. Qual a importância da área de Segurança do Trabalho no ambiente de trabalho? & & & & & \\
\hline 3.Você usaria um jogo didático como uma das formas de treinamento profissional? & & & & & \\
\hline 4. Qual a importância da Segurança do Trabalho no desempenho de um profissional? & & & & & \\
\hline
\end{tabular}
Fonte: Os autores

O questionário foi aplicado em Universidades de Nível Superior e Técnico, com Professores da área de Segurança do Trabalho. 10 pessoas
(Quadros 2, 3, e 5) responderam a esse questionário e foram obtidas as seguintes respostas para os 4 itens questionados. 
QUADRO 2: RESPOSTA 1 DO QUESTIONÁRIO APLICADO

\begin{tabular}{|c|c|c|c|c|c|}
\hline Qual a importância de um jogo didático em sala de aula? & $\mathbf{1}$ & $\mathbf{2}$ & $\mathbf{3}$ & $\mathbf{4}$ & $\mathbf{5}$ \\
\hline Usuário 1 & & & & $\mathbf{X}$ & \\
\hline Usuário 2 & & & & & $\mathbf{x}$ \\
\hline Usuário 3 & & & & & $\mathbf{x}$ \\
\hline Usuário 4 & & & & $\mathbf{X}$ & \\
\hline Usuário 5 & & & & $\mathbf{X}$ & \\
\hline Usuário 6 & & & $\mathbf{X}$ & & \\
\hline Usuário 7 & & & & $\mathbf{X}$ & \\
\hline Usuário 8 & & & & $\mathbf{X}$ & \\
\hline Usuário 9 & & & & & $\mathbf{x}$ \\
\hline Usuário 10 & & & & & $\mathbf{x}$ \\
\hline
\end{tabular}

Fonte: Os autores

QUADRO 3: RESPOSTA 2 DO QUESTIONÁRIO APLICADO

\begin{tabular}{|c|c|c|c|c|c|}
\hline $\begin{array}{c}\text { Qual a importância da área de Segurança do Trabalho no } \\
\text { ambiente de trabalho? }\end{array}$ & $\mathbf{1}$ & $\mathbf{2}$ & $\mathbf{3}$ & $\mathbf{4}$ & $\mathbf{5}$ \\
\hline Usuário 1 & & & & & $\mathrm{x}$ \\
\hline Usuário 2 & & & & & $\mathrm{x}$ \\
\hline Usuário 3 & & & & & $\mathrm{x}$ \\
\hline Usuário 4 & & & & $\mathrm{x}$ & \\
\hline Usuário 5 & & & & & $\mathrm{x}$ \\
\hline Usuário 6 & & & & & $\mathrm{x}$ \\
\hline Usuário 7 & & & & & $\mathrm{x}$ \\
\hline Usuário 8 & & & & $\mathrm{x}$ & \\
\hline Usuário 9 & & & & & $\mathrm{x}$ \\
\hline Usuário 10 & & & & & $\mathrm{x}$ \\
\hline
\end{tabular}

Fonte: Os autores

QUADRO 4: RESPOSTA 3 DO QUESTIONÁRIO APLICADO

\begin{tabular}{|c|c|c|c|c|c|}
\hline $\begin{array}{l}\text { Você usaria um jogo didático como uma das formas de } \\
\text { treinamento profissional? }\end{array}$ & 1 & 2 & 3 & 4 & 5 \\
\hline Usuário 1 & & & $\mathbf{X}$ & & \\
\hline Usuário 2 & & & & $\mathbf{X}$ & \\
\hline Usuário 3 & & & & $\mathbf{X}$ & \\
\hline Usuário 4 & & & & $\mathbf{X}$ & \\
\hline Usuário 5 & & & & $\mathbf{X}$ & \\
\hline Usuário 6 & & & $\mathrm{X}$ & & \\
\hline Usuário 7 & & & & $\mathbf{X}$ & \\
\hline Usuário 8 & & & & $\mathbf{X}$ & \\
\hline Usuário 9 & & & & & $\mathbf{X}$ \\
\hline Usuário 10 & & & & & $\mathrm{X}$ \\
\hline
\end{tabular}

Fonte: Os autores

QUADRO 5: RESPOSTA 4 DO QUESTIONÁRIO APLICADO

\begin{tabular}{|c|c|c|c|c|}
\hline $\begin{array}{c}\text { Qual a importância da Segurança do Trabalho no desempenho de } \\
\text { um profissional? }\end{array}$ & 1 & 2 & 3 & \begin{tabular}{l|l}
4 & 5
\end{tabular} \\
\hline Usuário 1 & & & & x \\
\hline Usuário 2 & & & & $x$ \\
\hline Usuário 3 & & & & $\mathrm{x}$ \\
\hline Usuário 4 & & & & $\mathbf{x}$ \\
\hline Usuário 5 & & & & $\mathrm{x}$ \\
\hline Usuário 6 & & & & \\
\hline Usuário 7 & & & & $\mathrm{x}$ \\
\hline Usuário 8 & & & & $x$ \\
\hline Usuário 9 & & & & \\
\hline
\end{tabular}




\begin{tabular}{|c|c|c|c|c|c|}
\hline $\begin{array}{c}\text { Qual a importância da Segurança do Trabalho no desempenho de } \\
\text { um profissional? }\end{array}$ & $\mathbf{1}$ & $\mathbf{2}$ & $\mathbf{3}$ & $\mathbf{4}$ & $\mathbf{5}$ \\
\hline Usuário 10 & & & & & $\mathrm{x}$ \\
\hline
\end{tabular}

Fonte: Os autores

De acordo com o questionário aplicado, no primeiro item, a maioria dos usuários responderam os quesitos 4 e 5 , que classificam esse item como muito importante. O mesmo padrão seguiu em todos os outros itens do questionário. Não houve nenhum item que foi marcado no quesito "pouco importante". E assim, deu-se continuidade ao processo de desenvolvimento do jogo.

\subsection{Custos}

Os materiais utilizados para a confecção do jogo em questão foram todos comprados na própria cidade. Os custos dos materiais foram assim esquematizados (Quadro 6):

QUADRO 6: CUSTOS DOS MATERIAIS

\begin{tabular}{|c|c|}
\hline Materiais & Custo \\
\hline Dado & $\mathrm{R} \$ 2,00$ \\
\hline Peões & $\mathrm{R} \$ 8,17$ \\
\hline Cartas/tabuleiro & $\mathrm{R} \$ 26,00$ \\
\hline Pasta & $\mathrm{R} \$ 2,20$ \\
\hline TOTAL & $\mathrm{R} \$ 38,37$ \\
\hline
\end{tabular}

Vale salientar que foram comprados materiais individuais, por isso o custo fica mais alto. Se o jogo fosse produzido em larga escala, com fornecedores que nos vendessem diretamente o material certamente o custo seria bastante reduzido. Outro custo que não foi levado em consideração é o da mão de obra. Nesse caso, as idealizadoras do jogo que criaram as perguntas, dicas e regras gerais.

\subsection{Aquisições e instruções de uso}

O jogo, inicialmente, será projetado para uso em sala de aula. Devido ao estudo em questão ter desenvolvido um protótipo do Jogo Trilha Segura, o mesmo ficará disponível na Universidade Federal Rural do Semiárido, podendo ser expandido para outras universidades, bem como poderá. Também, ser aperfeiçoado para realizar um melhor desempenho e adicionar novas sugestões que venham a contribuir para melhorar o jogo.

\subsubsection{Regras}

Público alvo: Alunos dos cursos de engenharia e técnicos.

Participantes: 2 equipes, cada equipe com seus participantes. Não existe um número mínimo e nem máximo para os participantes de cada equipe. Um avaliador, que funcionará como Juiz do Jogo.

Componentes: 1 trilha, 1 baralho, com 30 perguntas e 10 dicas. 2 peões. 1 Dado.

Entendendo o jogo: É importante que os jogadores leiam com atenção as ideias do jogo, para facilitar o seu entendimento.

Objetivo: Ser a primeira equipe a chegar, com seu peão, no final da trilha.

Preparação: Antes de iniciar o jogo, ler as regras, definir o juiz, responsável por definir decisões importantes no jogo, pois irá avaliar o desempenho de cada equipe e definir o seu número de participantes, bem como ler as perguntas e dicas do baralho. 
Cada equipe deve colocar o seu peão no início do tabuleiro.

Como jogar: Os jogadores decidem entre si qual equipe iniciará o jogo, começando a se movimentar na trilha quando acertar uma pergunta, avançando as casas, até chegar ao final do tabuleiro. Caso a equipe não consiga terminar a etapa, o peão permanece no mesmo lugar e espera a outra jogada para repetir a operação. A quantidade de casas que cada peão irá andar dependerá do número que o dado apresentar e, claro, se o peão, no caso a equipe, acertar a pergunta. Quando o peão precisar voltar casas e caso ele pare em cima de uma casa com o nome "dica", ele não terá o direito de usar uma dica, visto que somente será válido o uso da dica dos peões que estão avançando casas.

Tabuleiro: Todas as casas do tabuleiro estão marcadas com números e, algumas, com dicas. Foram escolhidas 20 casas para representar o tabuleiro, visto que por ser um jogo didático utilizado em sala de aula, ficaria cansativo o uso de muitas casas.

Vencedor: Vence o jogo, o peão que chegar ao final do tabuleiro.

\subsubsection{Apresentação do Manual}

Este manual fornece as instruções gerais e específicas para a realização do jogo utilizando o material fornecido, no caso, o "kit" com todos os materiais necessários para o jogo.

No manual são apresentados todos os procedimentos que deverão ser feitos pelos participantes e pelo coordenador (es) para a viabilização do jogo.

\subsubsection{Apresentação do jogo}

O jogo em questão, que foi denominado Trilha Segura, é formado por um tabuleiro, com perguntas e dicas na área de segurança do trabalho e tem como objetivo aplicar técnicas de segurança, através do desenvolvimento de estratégias que busquem a melhoria do ambiente de trabalho. Assim, por ser um jogo, exige a presença de participantes para ser colocado em prática.

\subsubsection{Identificação dos participantes}

- Equipes: Duas equipes. A equipe que chegar ao fim do tabuleiro e responder corretamente as perguntas, vence $\mathrm{o}$ jogo.

- Juiz: Um juiz por partida, que avaliará as respostas das equipes e decidir se está condizente com a resposta do cartão de pergunta.

\subsubsection{Modelo Reduzido do Jogo}

A Figura 3 mostra o modelo reduzido da trilha do jogo, cartas e peças utilizadas.

FIGURA 3: MODELO REDUZIDO DA TRILHA

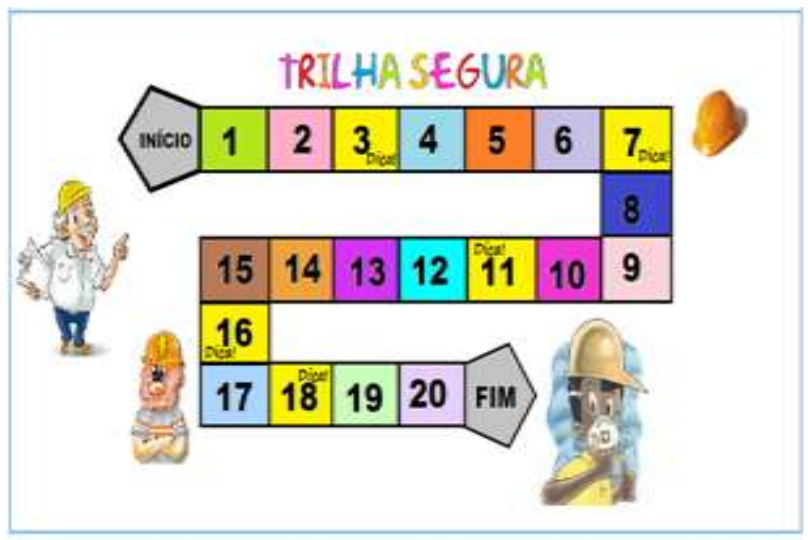

Fonte: Os autores 


\subsubsection{Cartas utilizadas}

As Figuras 4 e 5 mostra o modelo das cartas de perguntas e dicas utilizadas no jogo.
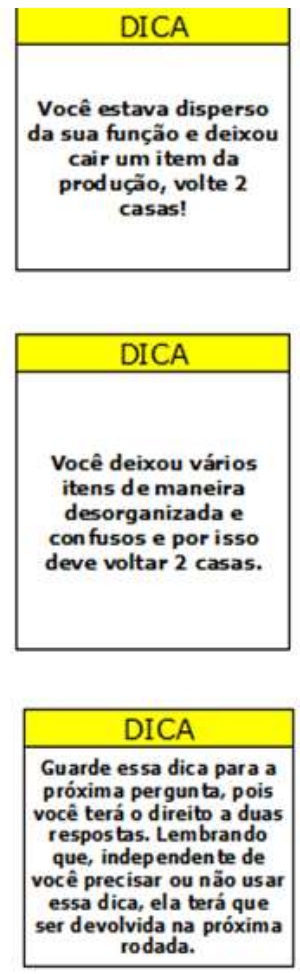
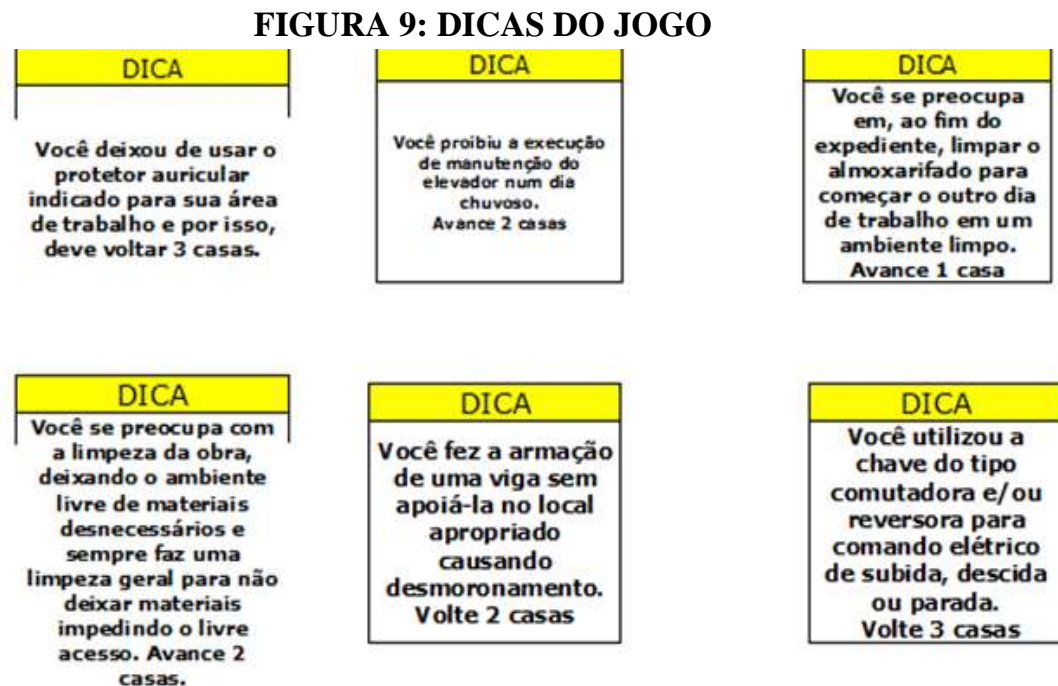

Avance 1 caso.

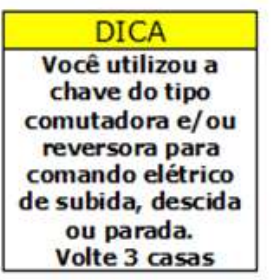

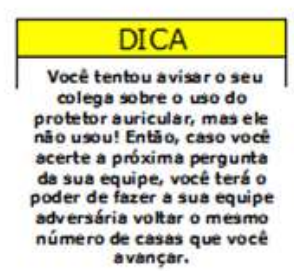

Fonte: Autores, 2012

\section{Considerações finais}

Após a realização de todo o processo que compôs a criação do projeto em estudo, foi feita a apresentação das ideias e do jogo didático, objetivando auxiliar os alunos com interesse na área de segurança do trabalho, para melhor fixação dos assuntos abordados nessa disciplina. Todo o processo foi feito através de pesquisas e reuniões com os criadores do projeto, de modo a chegar à ideia final. Dessa forma, foi feito uma pesquisa de mercado para saber se o jogo realmente seria válido e cumpriria seu papel inicial, que visa ajudar estudantes e professores a melhorar a dinâmica de uma aula e melhorar a compreensão do assunto tratado pelo jogo. Por fim, o jogo foi desenvolvido até chegar ao seu protótipo final.

Nesse estudo, todas as ideias desenvolvidas servem como sugestão para que futuramente sejam amadurecidas e melhoradas para um melhor resultado do jogo. Mas, estima-se que com a utilização do jogo didático, os alunos poderão ter uma aula mais dinâmica, um maior interesse em aprender o assunto e uma melhor fixação do mesmo. Assim, fica a sugestão desse projeto para aplicar em sala de aula e 


\section{ReLAInEF}

melhorar o desempenho dos alunos no

aprendizado, no caso do estudo, na disciplina de Segurança do Trabalho. E caso alguma empresa tenha interesse em utiliza-lo no ambiente de trabalho, também fica a proposta, visando melhorar o conhecimento de seus funcionários e melhorar no rendimento profissional.

FIGURA 10: PERGUNTAS DO JOGO

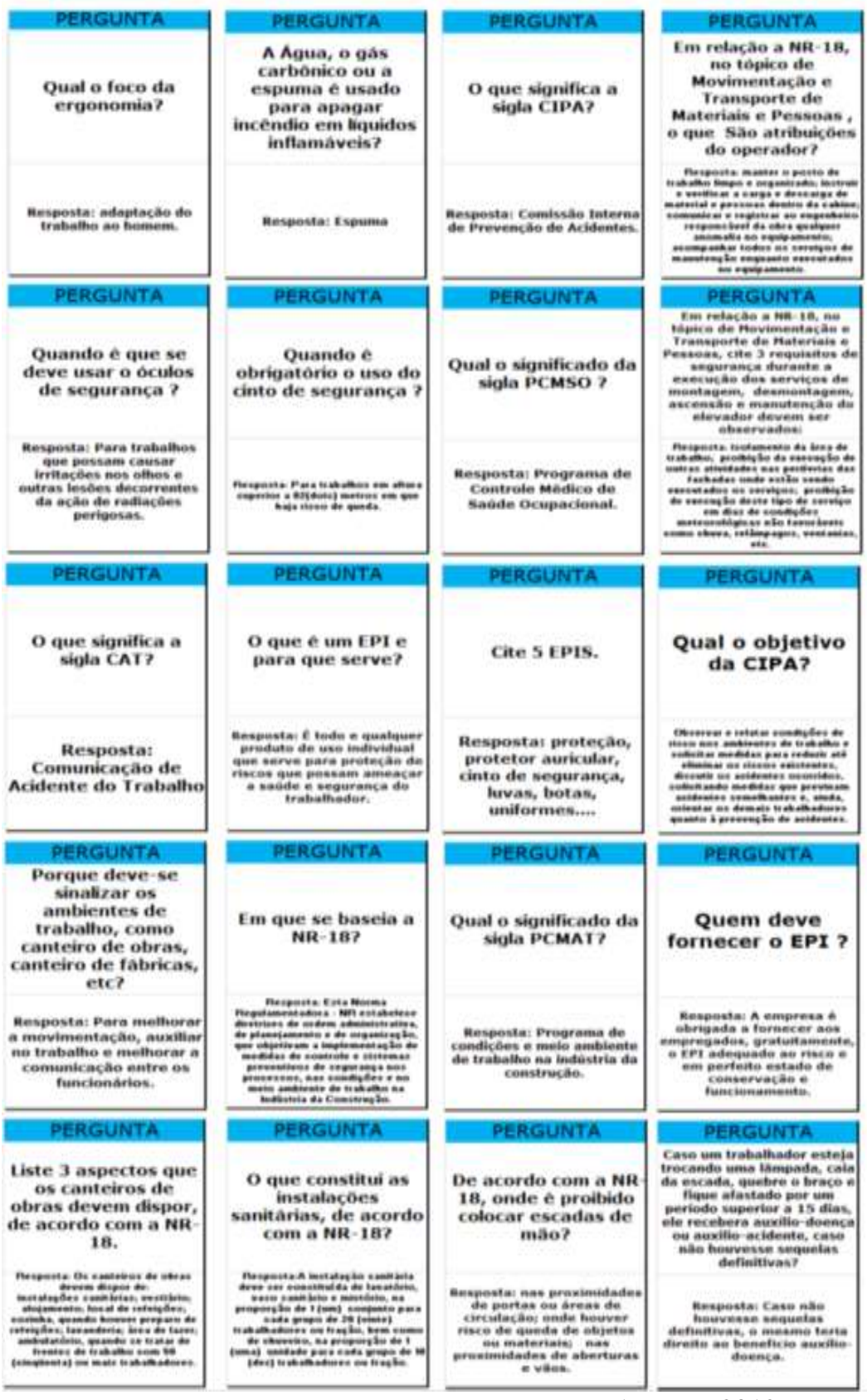

Fonte: Autores, 2012

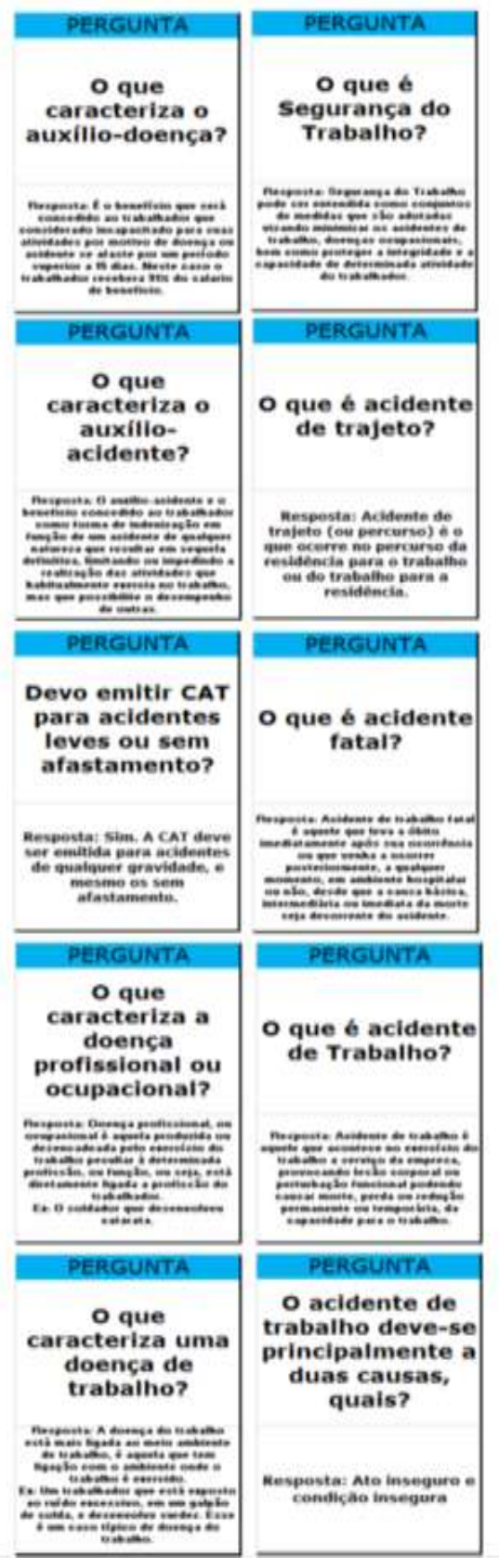




\section{Referências}

ARAUjO, R. P. Sistemas de Gestão em Segurança e Saúde no Trabalho: uma ferramenta organizacional. Joinville: Monografia Apresentada à Universidade de Santa Catarina para obtenção de título de especialista em Segurança do Trabalho, UDESC 2006.

CHIAVEnATO, I. Higiene, Segurança e Qualidade de vida. In: Gestão de pessoas: o novo papel dos recursos humanos nas organizações. Rio de Janeiro: Elsevier, 1999.

Faria, A. R. de. O desenvolvimento da criança e do adolescente segundo Piaget. Ed. Ática, $3^{\circ}$ edição, 1995

KISHIMOTO, Tizuko Morchida. O jogo, brinquedo, brincadeira e a educação. São Paulo, Cortez, 1999.

Legislação Comentada: Normas Regulamentadoras de Segurança e Saúde do Trabalho/Serviço Social da Indústria SESI. Departamento Regional da Bahia. Salvador, 2008.

MACHADO, Carlos Cardoso. Colheita Florestal. Viçosa: UFV, 2002.

PEREIRA, P.F. Norma Regulamentadora 18 (NR-18). Comentários, 2010

ROMANEL, F. B. Jogo "Desafiando a produção": uma estratégia para a disseminação dos conceitos da construção enxuta entre operários da construção civil. Dissertação apresentada ao Programa de Pós-Graduação em Construção Civil. UFPR Curitiba/2009

ROZENFELD, H.; FORCELLINI, F.A.; AMARAL, D.C.; TOLEDO, J.C.; SILVA, S.L.; ALLIPRANDINI, D.H.; SCALICE, R.K.; Gestão de desenvolvimento de produto. São Paulo: Saraiva, 2006.

SLACK, N.; CHAMBERS, S.; JOHNSTON, R. Administração da produção. São Paulo: Atlas, 2009. 